\title{
An exploratory study on the building information modeling adoption in United Arab Emirates municipal projects-current status and challenges
}

\author{
Senthilkumar Venkatachalam, ${ }^{1, *}$ \\ ${ }^{1}$ Sustainable Construction Materials and Structural Systems Research Group, Department of Civil and \\ Environmental Engineering, University of Sharjah, Sharjah, United Arab Emirates
}

\begin{abstract}
Many modern complex building projects in the public and private sectors are characterized by its poor information management which is manifested by time and cost overruns around the world. Building Information Modelling (BIM) is currently being adopted around the world with various countries mandated its implementation. In specific, the implementation of BIM is rapidly growing in developed countries such as USA, UK, Singapore and Australia, with government mandate through devising strategies and initiatives to increase the adoption. The implementation of BIM in United Arab Emirates (UAE) and other developing countries lags behind due to the existence of numerous implementation barriers. This study explores the current status of BIM implementation in the UAE municipalities, further explores the people, process and technology readiness towards BIM adoption in the UAE building projects. Further the study also explores the current challenges against the BIM adoption. The study adopts a positivists approach by collecting data through questionnaires, a sample of sixty participants across the UAE municipalities from different states were selected randomly to acquire the data. The collected data is statistically analyzed to obtain the findings. The analysis results showed that there are inadequate people and process related readiness towards BIM adoption whereas the technology readiness does exist. The same also was reflected in further analysis on BIM adoption barriers as the challenges. Further the paper also discusses the possible strategies adopted around the world through literature to address the explored challenges in the study
\end{abstract}

\section{Introduction}

Construction projects are complex accomplishments that require diverse purposed stakeholder's involvement to accomplish the common project outcomes [1]. The diversity on their purpose is through its components, people and processes variations and its complex

\footnotetext{
* Corresponding author: svenkat@,sharjah.ac.ae
} 
relationships and interfaces [2]. This characterization brings complexities to the project delivery. These complexities are characterized in all aspects of the projects, including people, process and technology etc., [1]. These three aspects are connected through the project information. Huge amount of information is been generated in any construction projects. These instills the complexity further and evident the collaboration related inefficiencies in their project multi-objective decision making process.

The use of IT had been so far proven to be effective in handling these huge project information, it is largely discrete until the advent of the Building Information Modeling (BIM). BIM is the process of capturing the information through the development of $\mathrm{nD}$ models and use of these digital models and associated tools to facilitate planning, design, construction, and operation during the project lifecycle[3]. Once modelled, it contains a wealth of data about the designed entity and it is useful for representing several views of project data including two dimensional (2D), three dimensional (3D), four dimensional (4D, schedule), five dimensional (5D, cost), six dimensional $(6 \mathrm{D}$, operations and maintenance) forms[4][5]. The BIM implementation in UAE municipalities is inconsistent and investigating the current status of BIM adoption, the related challenges and the possible future strategies becomes paramount important to efficiently deliver the construction projects. Hence this study aims to identify the BIM adoption status, challenges, and drivers in UAE municipal project delivery. The following sections outlines the literature review related to the study. Followed by the adopted research method. The fourth section outlines the analysis of the responses obtained followed by the discussions and conclusions.

\section{Literature review}

The scenario of complexity and its related collaboration inefficiencies are very much similar in the United Arab Emirates (UAE) construction industry, which hosts multiple stakeholders from all around the world to work for their common objectives in UAE construction projects [6]. Building Information Modelling (BIM) is currently being adopted around the world with numerous countries mandating its implementation on public projects through legislation. This process has driven the development of BIM standards and specifications to streamline design data prior to collaboration and to meet regulatory requirements. Although BIM technologies globally are similar, many countries have developed context-specific BIM specifications to accommodate differences in their design processes, procurement processes and government policies.

BIM implementation has gained prominence in the last decade, in the United States of America, Singapore, United Kingdom, Australia and some Nordic countries[7][8].Further, many of the Asian and Middle Eastern countries started adopting the BIM on their private sector projects [9].Further, Dubai to host EXPO 2020, necessitates many more innovative and complex infrastructure projects to be built. Dubai Municipality mandated the implementation of BIM in its significant capital projects from 2014[6]. Though there are limited research to precisely measure the benefits of BIM at the project level [10], its impact in long term has been shown as huge benefits in most of the literature and further the implementation benefits also vary from project to project [11]. Some of these reported benefits to the construction companies are in terms of its improved collaboration, less lead time, less clashes, less rework and overall improvement in the project outcomes [12]. These advantages encourages more and more adoption in the construction industry around the world [13] especially in the private sectors in UAE.

BIM doesn't produce the guaranteed results always, if an appropriate modifications are made in the existing project delivery systems in terms of the three above discussed aspects such as the people, process and technology[14].Figure 1 depicts the Word cloud depicting prominence of issues studied in BIM research in the literature. There are many aspects in 
construction projects in which BIM implementation has a leverage. However this study focuses on some of the prominent important and basic aspects which paves the way to progressively adopt BIM.

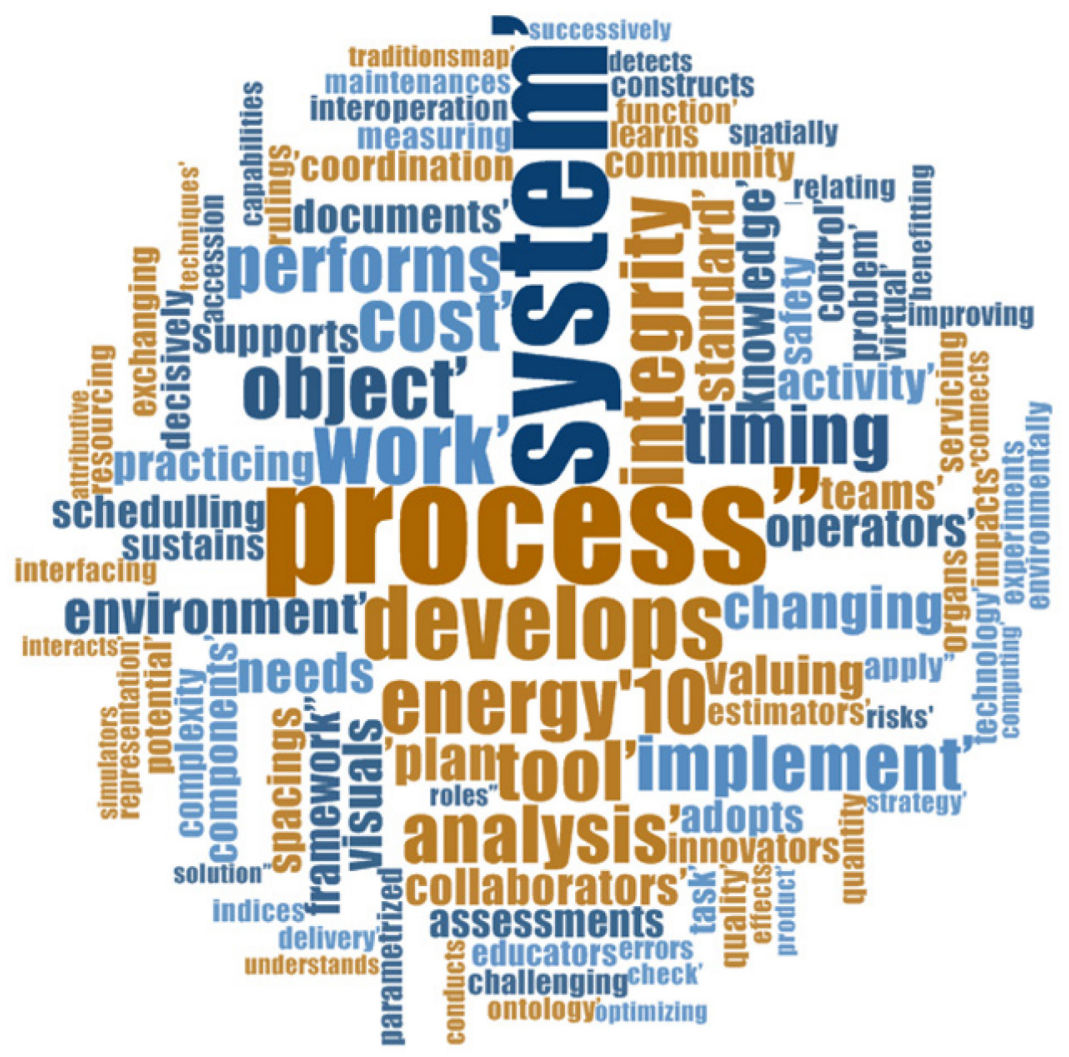

Fig. 1. Word cloud depicting prominence of issues studied in BIM research.

People related barriers include, the reluctance to change, lack of skilled professionals, high initial cost of implementing BIM standards and specifications. This includes the cost of down time within the organization in order to change the current design workflow. It also includes the cost of continually educating and training employees in terms of the implementation of BIM standards and specifications, keeping in mind that there will be a learning curve involved for even the most proficient BIM user [15].This further will have effect on the team formation and its related organizational structure. Empowering the people with the appropriate skills and competencies become another major challenges that the construction organizations face during the implementation of the BIM. There are very limited courses taught BIM standards and specifications in the developing nations where BIM is still in the premature level of adoption. This results in BIM trainers themselves being novices. On the back of that employees in construction organizations are generally resistant and reluctant to learn new tools and work flows as they perceive this as a waste of time and a hindrance to their productivity.

The process related challenges often originates through the legal and contractual barriers of BIM standards and specifications include the uncertainty of legal liability amongst AEC stakeholders. The uncertainty on the accuracy of BIM model data may 
necessitates contractual clause modifications, creation and deletion of processes, roles and responsibilities among the participants [15].

Technology related barriers are otherwise tools barriers include the vague specifications about the level of details during various design stages and the amount of data, its standard format, interoperability etc., this may be nonspecific, indefinite and impractical in some projects. This may lead to adverse effect on the project data delivery and end up with the inefficiency on the final process, product and mistrust among the participants. Further, the tools barrier also include designers' BIM efficiency and the lack of BIM training and support [16]. Open interoperability may also become an issue as not all design stakeholders are utilizing the same BIM software packages in a common data environment.

Though the categorization can be specified as people, process and technology, some of the challenges under these categories may also take more than one facet. For example, one of the process related challenges associated with BIM implementation is the resistance offered by the people on the change of existing work practices and culture [14][17][18]. The categorization for the above challenge may be in terms of the people related as its behavioral oriented or it can be process oriented as the workflow dictates the people to behave in a certain manner.

Around the world there are many BIM adoption and implementation strategies introduced mainly through a TOP down (Client) approach throughout the building lifecycle [15][19][20]. Among which the important and successful ones are from the US, Nordic Singapore and more recently the UK. Local governments should play a vital role in overcoming these barriers by means of enforcing legislative BIM standards and specifications on construction projects. This enforcement can lead to the promotion of technological BIM innovation by means of driving national leadership and reform [21]. The recent Dubai Municipality's BIM mandate is an example for such pattern of BIM implementation. However, the mandate without the necessary social and infrastructure climate or BIM adoption readiness may not give the desired results. There is another approach through which the BIM is implemented in most of the pre mature adopters of BIM such as the developing nations, which is proceed with the implementation without any national or reginal standards and guidelines. Many literature have reported the pros and cons of the two approaches [15][20]. However, the top down Government involvement basically helps to facilitate a coordinated rather than fragmented approach to the adoption and implementation of BIM [19].

There have been more and more standards and guidelines developed by different countries [20][8]. These standards and the guidelines were developed to suit to their local project supply chain contexts. These standards and guidelines are developed through mainly governmental initiatives but not limited to the involvement of the research universities, educational and training institutes, professional councils and private sector collaborations.

Among all the Government led BIM implementation initiatives, the UK model is more structured and effective one[15]. The initiatives have produced more and more guidelines and standards documents to guide building information creation, sharing, storing, use, reuse as well as collaborative relationships based on BIM within the construction supply chain. These include, but not limited to:

PAS 1192-2:2013 - Specification for information management for the capital/delivery phase of construction projects using building information modelling

PAS 1192-3:2014 - Specification for information management for the operational phase of assets using building information modelling

BS 1192-4:2014 - Specification for collaborative production of information and fulfilling employer's information exchange requirements using COBie 
PAS 1192-5:2015 - Specification for security-minded building information modelling, digital built environments and smart asset management

COBie (Construction Operations Building Information Exchange) - a data format for the publication of a subset of building model information focused on delivering building information not geometric modelling.

With these background the current study explores the current status of the BIM implementation in UAE municipal project delivery and capture the challenges also to propose a strategy to overcome the same. The following section explains the adopted research method in this study.

\section{Research methodology}

The study adopts a positivism as a research philosophy, which necessitates the deduction in the research approach. The questionnaire survey is administered as a research strategy to obtain the data from the municipal project participants. The study is a cross-sectional one and is administered towards the end of 2015 for about a month. There were 100 questionnaire distributed among the municipal project stakeholders from the different emirates. There were 60 valid responses obtained. The respondents include different stake holders which include contractors, sub-contractors, engineers, architects, project managers, government officials, facility managers, quantity surveyors and the municipal administrative authorities. Though the questionnaire was distributed proportionately to all the emirates the response spectrum shows dominance in only three emirates. However, most of the respondents do executes project in other emirates as well hence the generalizability of this exploratory study is not affected by the low respondent numbers in some of the states. Also there were only 45 respondents who would like to answer the BIM related questions the others simply not answered. There were five sections of questions were asked to the respondents through the questionnaire. The first sections captured the respondent detail which includes the stakeholder's primary job title, emirates in which he did serve, how many projects he did execute etc. The second section asks the awareness and application of the BIM in various building project life cycle stages, the third section of the questions asks the opinion of the respondents about the drivers for the BIM adoption now and in future. The fourth section of the questionnaire asks the readiness of their firms in BIM adoption in terms of people process and technology related factors. The final section lists the challenges on BIM adoption followed by some open ended questions regarding their opinion on future BIM adoption and the strategies. The questionnaire responses are analyzed using simple descriptive statistics. The obtained results are triangulated with further 3 interviews among the participant stakeholders.

\section{Analysis and results}

The 60 returned questionnaire responses were carefully captured in a excel sheet for further analysis. The question regarding the awareness revealed that only 48 out of 60 respondents are aware of BIM. Among the 48 only 45 were accepted to participate in further survey. Figure 2 showed the perceived level of adoption through a radar plot, the respondents who were willing to participate in the BIM related questions were asked about the potential application of BIM. The analysis showed that the intention or the adoption status that BIM are for the purposes of the $3 \mathrm{~d}$ Modeling and walkthrough, class detection and record keeping purpose only. All other benefits are yet to be realized among the municipal project stakeholders. This reveals that the participants are lack with awareness about the BIM benefits. 


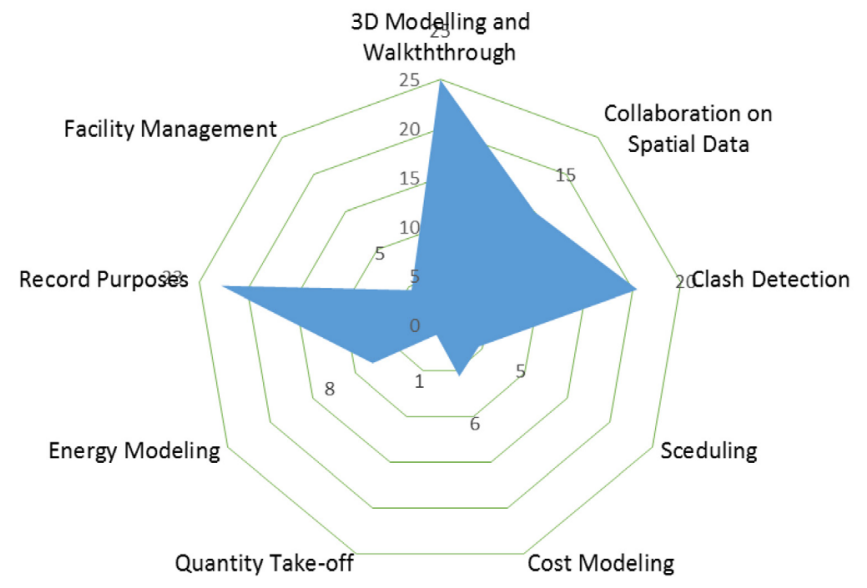

Fig.2. BIM application in Project Delivery Processes-Status

Further the questions regarding the readiness of BIM adoption reveled that there exists a lack in terms of the people and process related aspects however the technology readiness exists among the UAE municipal project stakeholders. Figure 3 showed the results in a bar chart plot. The drivers which may motivate the users to adopt BIM also been asked among the project stakeholders and the results are shown in figure 4. Overall, the drivers mentioned in figure 4 are acknowledged by most of the respondents. However, widely the respondents perceived that the BIM has advantages during the design stage of the projects. This is evident in figure 4 that many respondents agreed that they get motivated as BIM improve the design quality, reduce design time, design collaboration, reduce design rework etc.

Figure 5 showed the challenges that the participants perceived towards BIM implementation in UAE's municipal projects. It is expressed through a weighted average of the Likert scale responses. The scale is ranging between 1 to 5 as strong disagreement (with the score of 1) to the strong agreement (with the score of 5).It is observed through the radar plot in figure 5 that the top three challenges which are agreed by most of the respondents are the inadequate top management support, higher cost associated with the BIM implementation and the inadequate statutory support. Though there are other important challenges which are listed as lack of BIM professionals, lack of BIM related information, lack of company policy, reluctance to use the technology etc. 

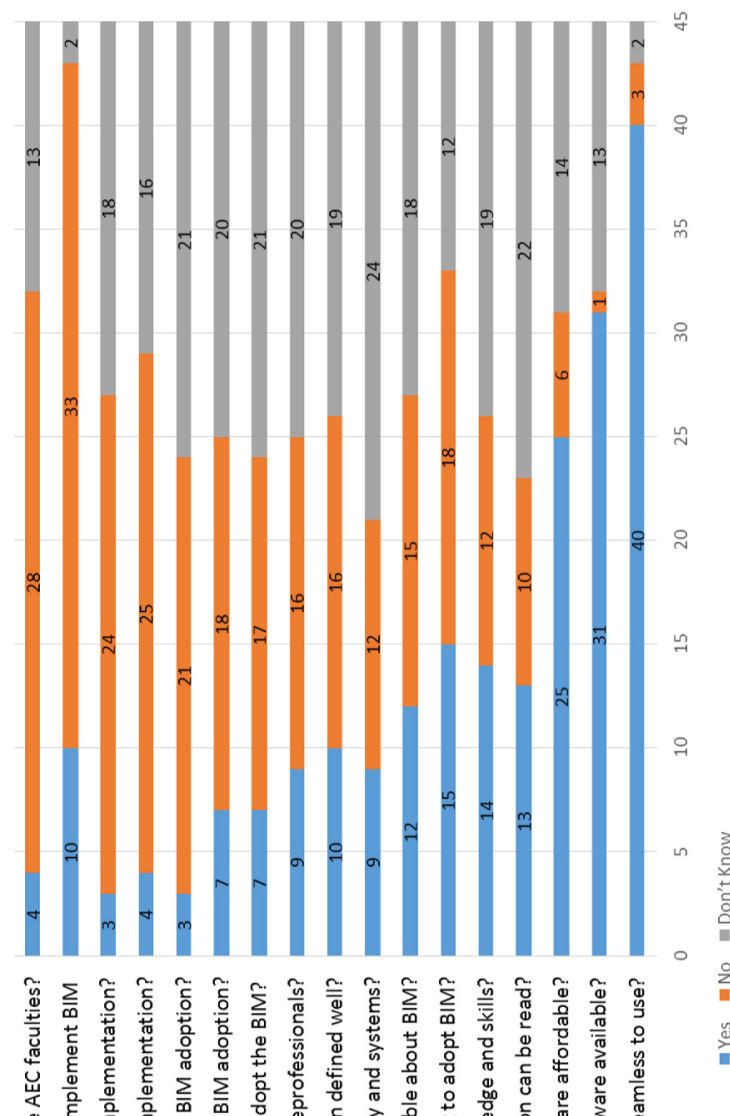

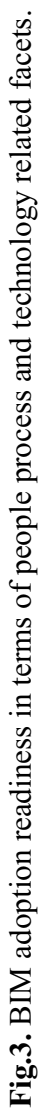


m Strongly Disagree $\quad$ Disagree $\quad$ Neither Disagree Nor Agree $=$ Agree $\quad$ Strongly Agree

To meet the regulatory mandate

To manage the pressure from competitors

To address the client's contractual agreement

To automate the construction schedule and progress updates

Desire for innovation

To faciliate more Off site activities

To optimize the whole life cycle cost of the project

To facilitate facility management

To save costs through reducing the RFIs

To optimaly sequence design process flow

To reduce costs because BIM reduces re-work

To improve overall project quality

To manipuilate the appropriate construction activities

To improve communication and collaboration among stakeholders

To save time during design process

To improve the quality of design
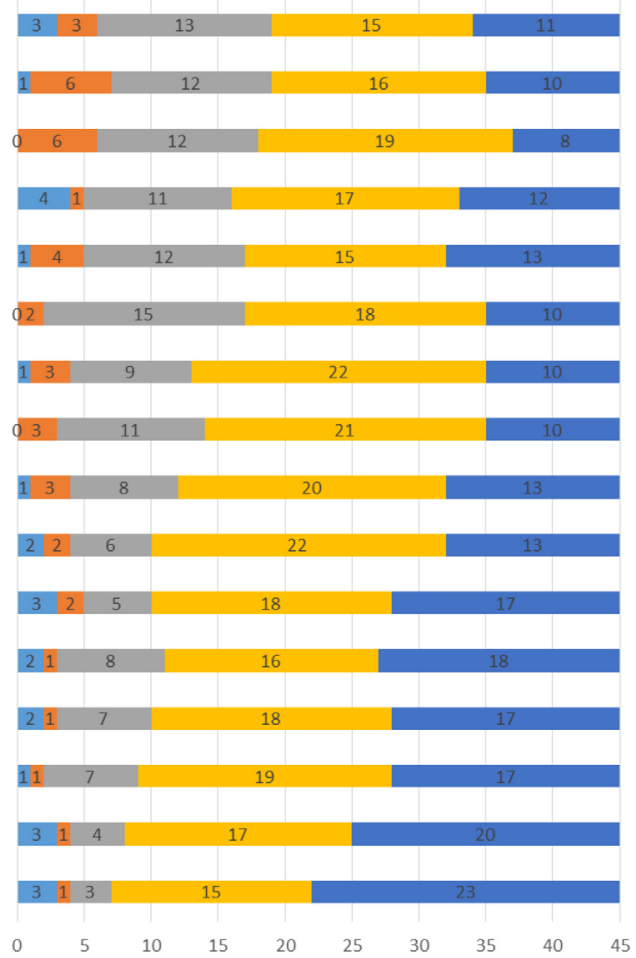

Fig.4. Perceived drivers towards BIM adoption.

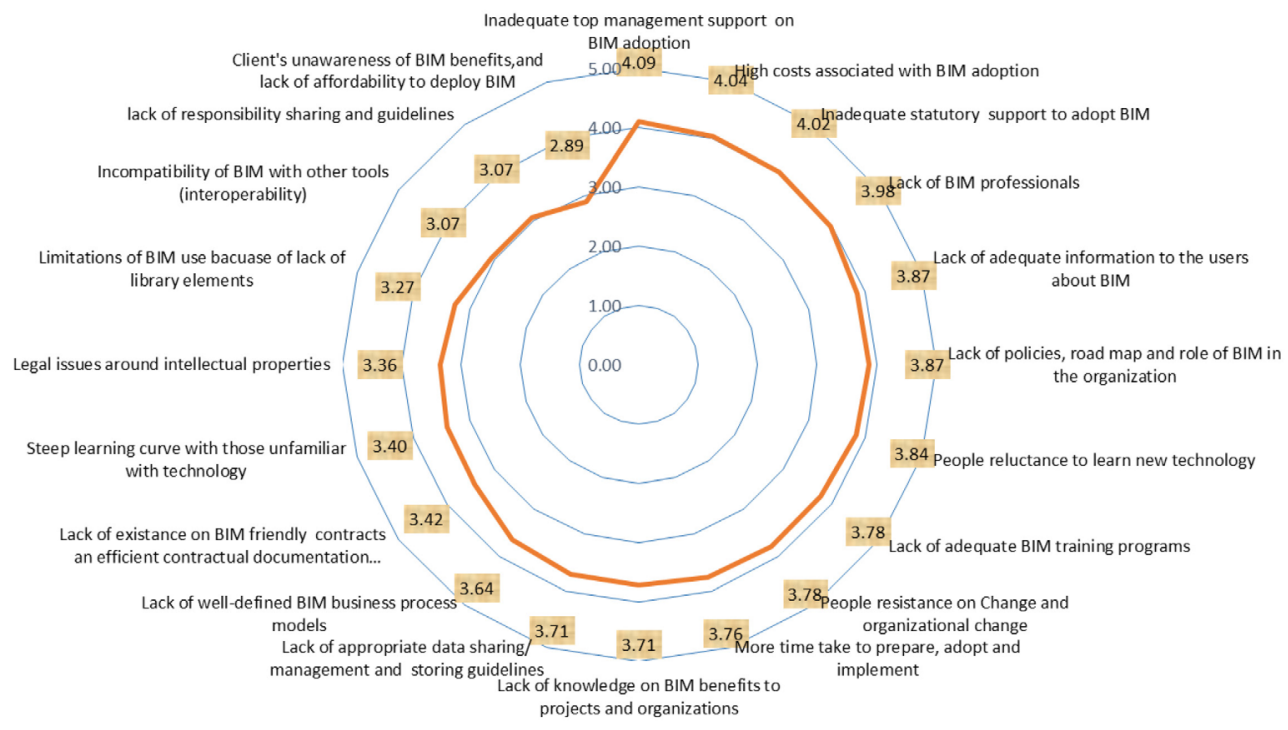

Fig.5. Perceived challenges towards BIM adoption- expressed in weighted average. 


\section{Discussions and conclusions}

BIM is being implemented in the UAE for many years, however its implementation within the municipal projects are very low. There are initiatives such as Dubai Municipality's mandate to adopt BIM for the high capital projects. However, the adoption is still less in the projects and especially at the municipal level. It is evident from the study that the stakeholders awareness about BIM do exist however the adoption is limited. It is also evident from the survey that the perceived BIM application is mostly during the design stage. Further, it is also observed that the technological readiness exists within the study context but the people and process doesn't. To improve this end, it is necessary to have the nationwide Building Information Modeling standard and guidelines. Without this, the adoption becomes very much discrete and inconsistent in terms of its benefits realization.

Further, the respondents also perceived that the drivers which are identified in the literature is all considered and accepted to improve the BIM adoption. The top three challenges which were perceived as impediment to the BIM adoption are the inadequate top management support, higher cost associated with BIM adoption and the inadequate nationwide statutory support structure. This study results are lack with rigorous evidences because of low number of respondents, however, the findings from the study is adequate to an exploratory study. For future studies, it is recommended to have larger sample size with rigorous statistical analysis is needed to further reinforce the findings.

\section{References}

1. Fang, C., and Marle, F. Dealing with project complexity by matrix-based propagation modelling for project risk analysis.Journal of Engineering Design, 24(4), 239-256. (2013).

2. Antoniadis, D., Edum-Fotwe, F., Thorpe, A., and McCaffer, R. Exploring Complexity in Construction Projects.1-6. (2008).

3. Azhar, S., Hein, M., and Sketo, B. "Building Information Modeling (BIM): Benefits, Risks and Challenges.” Aurburn. (2008).

4. Arayici, Y., Coates, P., Koskela, L., Kagioglou, M., Usher, C., and O’Reilly, K. "BIM adoption and implementation for architectural practices." Structural Survey (2013).

5. Love, P. E. D., Edwards, D. J., and Han, S. "Bad apple theory of human error and building information modelling: A systemic model for BIM implementation." 349354(2011a).

6. Mehran D., Exploring the Adoption of BIM in the UAE construction industry for AEC firms. Procedia Engineering 145110-1118. (2016).

7. Alabdulqader, A., Panuwatwanich, K., and Doh, J.-H. "Current use of building information modelling within Australian AEC industry." The Thirteenth East AsiaPacific Conference on Structural Engineering and Construction (EASEC-13), C-3-1. (2013).

8. Wong, A. K. D., Wong, F. K. W., and Nadeem, A. “Attributes of Building Information Modelling Implementations in Various Countries." Architectural Engineering \& Design Management, 6(4), 288-302(2010a).

9. Cao, D., Li, H., and Wang, G. "Impacts of Isomorphic Pressures on BIM Adoption in Construction Projects." Journal of Construction Engineering and Management, 140(12), 04014056(2014).

10. Lu, W., Peng, Y., Shen, Q., and Li, H. "Generic Model for Measuring Benefits of BIM as a Learning Tool in Construction Tasks." Journal of Construction Engineering \& Management, 139(2), 195-203(2013a). 
11. Giel, B., and Issa, R. "Return on Investment Analysis of Building Information Modeling in Construction." Journal of Computing in Civil Engineering, 27(5), 511521. (2013).

12. Crotty, R. The impact of building information modelling: transforming construction. Routledge. (2012).

13. NBS. National BIM Report 2014. RIBA Enterprises Ltd (2014).

14. Rekola, M., Kojima, J., and Mäkeläinen, T. "Towards Integrated Design and Delivery Solutions: Pinpointed Challenges of Process Change." Architectural Engineering \& Design Management, 6(S1), 264-278(2010a).

15. Smith, P. "BIM implementation - Global strategies." 482-492(2014).

16. Davies, R., and Harty, C. "Implementing 'Site BIM': A case study of ICT innovation on a large hospital project." Automation in Construction, 30(0), 15-24(2013).

17. Porwal, A., and Hewage, K. N. "Building Information Modeling (BIM) partnering framework for public construction projects." Automation in Construction, 31, 204214(2013a).

18. Jung, Y., and Joo, M. "Building information modelling (BIM) framework for practical implementation." Automation in Construction, 20(2), 126-133(2011).

19. Atkinson, L., Amoako-Attah, J., and B-Jahromi, A. "Government's influence on the implementation of BIM." 520-527(2014).

20. Shou, W., Wang, J., Wang, X., and Chong, H. Y. "A Comparative Review of Building Information Modelling Implementation in Building and Infrastructure Industries." Archives of Computational Methods in Engineering, 22(2), 291-308(2015).

21. Liu, Y., Zeng, N.-S., and Xu, B. "Research on the concept and framework of building information modeling ecosystem." 1799-1805. (2014) 